\title{
PROFIL SOFT SKILL DAN HARD SKILL MAHASISWA DALAM MEMASUKI DUNIA KERJA
}

\author{
Nabila Ikrima Jeklor Putri ${ }^{1}$, Lucy Fridayati ${ }^{2}$ \\ ${ }^{1}$ Dosen Pendidikan Kesejahteraan Keluarga, Universitas Negeri Padang \\ ${ }^{2}$ Prodi Pendidikan Kesejahteraan Keluarga, Fakultas Pariwisata dan Perhotelan, \\ Universitas Negeri Padang \\ Jl. Prof. Hamka Kampus UNP Air Tawar Padang \\ e-mail: nabilaikrimajeklorputri@gmail.com, lusifridayanti@fpp.unp.ac.id , \\ 11111961@fppunp.ac.id
}

\begin{abstract}
The study aims to describe and to know the profile of soft skills and hard skills of the college students to enter the work field. The type of research is quantitative descriptive research. The population of this research is the students of padang state university family welfare education study program totally 49 people. The sampling technique is total sampling that taking the entire population. The technique of collecting data is by transferring a questionnaire (Questionnaire) using Likert scale that has been tested for validity and reliability. The data were analyzed through descriptive analysis with the categorization method. The results of the study is the soft skills and hard skills profile of college students to enter the work field that included in high category are indicators of work ethics, collaboration, discipline, related to norms and the medium category are indicators of speaking skills and confidence.
\end{abstract}

Keywords: soft skills, hard skills, the work field

\section{PENDAHULUAN}

Pendidikan mempunyai peranan yang sangat penting untuk meningkatkan kinerja dan wawasan individu terutama bagi pembangunan bangsa dan negara. Salah satu lembaga pendidikan tersebut adalah Universitas Negeri Padang. Program Studi Pendidikan Kesejahteraan Keluarga berada dibawah naungan Jurusan Ilmu Kesejahteraan Keluarga. Program Studi Pendidikan Kesejahteraan Keluarga merupakan Program Studi Strata 1. Pendidikan Kesejahteraan Keluarga ini memiliki dua program keahlian, yaitu program keahlian Pendidikan Tata Boga dan program keahlian Pendidikan Tata Busana. Berdasarkan buku pedoman akademik (2018:40) Program Studi Pendidikan Kesejahteraan Keluarga (S1) mempunyai visi:Menjadi lembaga penghasil tenaga kependidikan profesional yang unggul di ASEAN dalam bidang Pendidikan Kesejahteraan Keluarga (Tata Boga dan Tata Busana) dan bidang 
industri, yang adaptif dan inovatif terhadap perkembangan Iptekk dengan bertaqwa kepada Tuhan Yang Maha Esa, berjiwa kebangsaan, berwawasan global dengan berpijak pada pilar-pilar kepakaran dan profesionalisme.

Berdasarkan visi yang telah ditetapkan dari program studi ini maka mahasiswa diharapkan untuk bisa terjun di dunia kerja seperti di bidang pendidikan, industri, maupun di bidang usaha. Dunia kerja tentu mempunyai syarat kemampuan yang harus dimiliki oleh calon pekerja sebagai penunjang dalam melakukan tugas-tugas yang akan ditemuinya. Selain hard skilldunia kerja juga membutuhkan tenaga kerja yang memiliki soft skill. Kemampuan ini merupakan karakteristik yang dimiliki individu dalam merespon lingkungannya. Dalam riset peranan soft skill Mitshubisi Riset Institute pada tahun 2000 yang dikutip oleh Elfindri dalam (Nissa Rizki, 2012:36), mempublikasikan hasil kajian tim risetnya yang menyatakan bahwa kesuksesan lulusan ternyata tidak ditentukan oleh kemampuan teknis dan akdemis/ hard skills sebagai berikut: $40 \%$ kematangan emosi dan sosial, 30\% proses menjalin networking, 20\% kemampuan academik dan $10 \%$ kemampuan finansial yang dimiliki.

Seiring dengan bertambahnya jumlah lulusan dari berbagai lembaga pendidikan tanpa dibarengi dengan jumlah lapangan kerja yang seimbang, maka akan timbul sistem seleksi tenaga yang ketat. Lulusan yang tidak mampu mengembangkan sikap, pengetahuan dan keterampilan yang sesuai standar nasional akan kalah dalam persaingan hidup yang berujung pada penambahan angka pengangguran.Hal tersebut dijelaskan oleh Badan Pusat Statistik Indonesia (BPS) menyebutkan, "Dilihat dari tingkat pendidikannya lulusan diploma dan universitas makin banyak yang tidak bekerja. Kenaikan jumlah pengangguran untuk lulusan Diploma adalah sebesar 8,5\% dan untuk S1 adalah 25\%".

Hasil penelitian Cici Yoma Riza (2013: 116) yang menyatakan "Mahasiswa lulusan PKK menghabiskan masa tunggu untuk mendapatkan pekerjaan selama 7 bulan". Hal ini terjawab dalam penelitian Tika Rusmiati (2016: 2) yang menyatakan "Lulusan memang belum siap untuk bekerja dan kompetensi yang dimiliki masih belum cukup dan karena kualitas lulusan sarjana yang belum sesuai dengan kebutuhan dunia kerja". Seharusnya mahasiswa telah memiliki hard skill yang memadai baik secara kognitif, afektif dan psikomotor. Serta soft skillyang merupakan modal utama dan paling besar dimiliki dalam diri sendiri (Nurhasanah, 2016: 4).

\section{METODE}

Jenis penelitian yang digunakan adalah penelitian deskriptif kuantitatif. Penelitian ini dilaksanakan di Jurusan Ilmu Kesejahteraan Keluarga Fakultas Pariwisata dan Perhotelan Universitas Negeri Padang. Penelitian ini dilakukan pada semester ganjil Juli-Desember 2019. Variabel penelitian ini terdiri dari dua yaitu soft skill (X1) dan hard skill (X2). Populasi penelitian ini adalah mahasiswa S1 Pendidikan Kesejahteraan Keluarga konsentrasi Tata Boga angkatan 2015 yang berjumlah 49 
orang. Teknik pengambilan sampel adalah dengan total sampling yaitu mengambil seluruh populasi. Jenis data dalam penelitian ini adalah data primer dan data sekunder. Teknik pengumpulan data yaitu dengan menyebarkan kuesioner (Angket) menggunakan skala likert yang telah teruji validitas dan reliabilitasnya. Instrumen penelitian yang digunakan adalah berupa kuesioner (Angket) yang harus diisi oleh seluruh sampel. Kuesioner (Angket) disusun menggunakan skala likert. Langkah yang dilakukan dalam analisis data ini adalah menentukan distribusi frekuensi, menentukan tingkat presentase danteknik klasifikasi.

\section{Hasil dan Pembahasan}

\section{HasilPenelitian}

Berdasarkan hasil olah data dari variabel dan indikator penelitian didapat hasil sebagai berikut.

\section{1) ProfilSoft Skill secara keseluruhan}

Histogram pengkategorian dapat digambarkan pada gambar 1 di bawah ini:

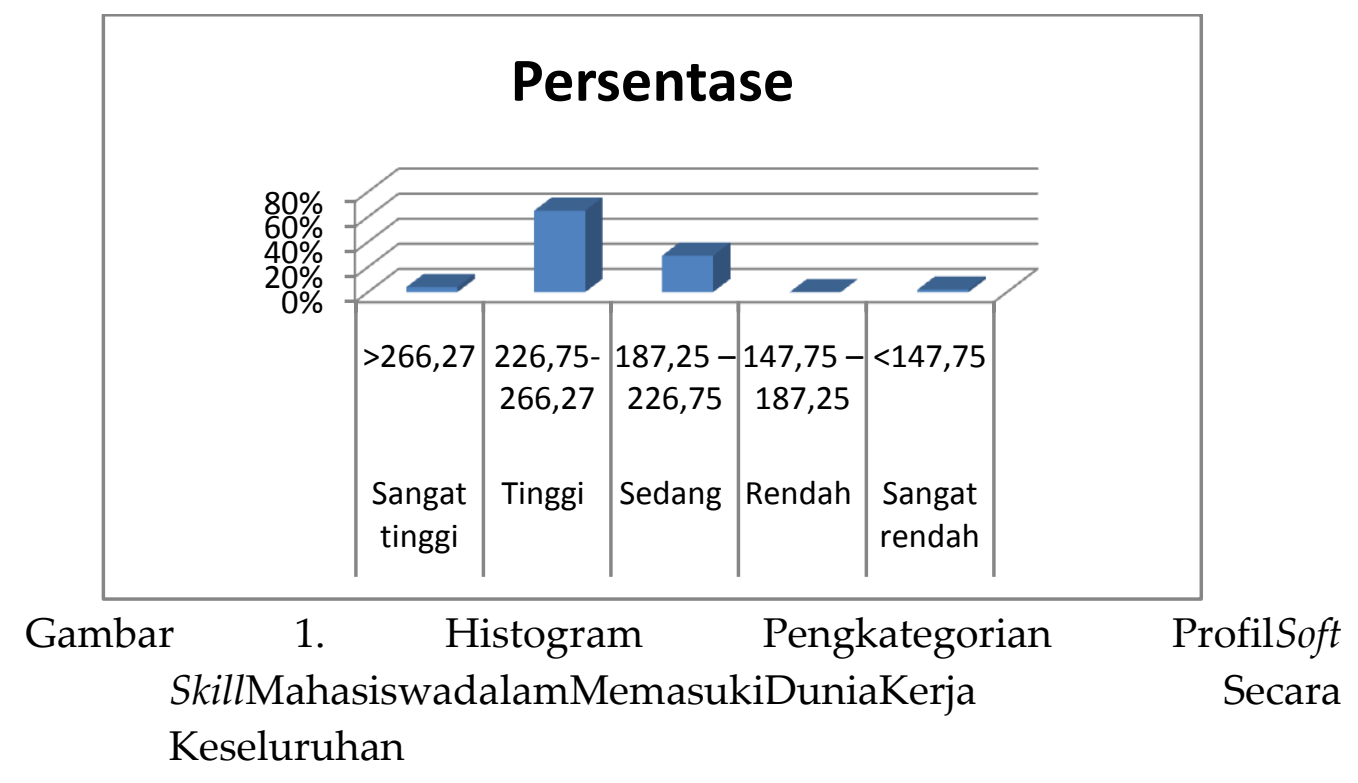

2) Deskripsi Data ProfilHard SkillMahasiswadalamMemasukiDuniaKerja Secara Keseluruhanberdasarkan masing-masing IPK dapat dilihat pada tabel 14 berikut ini: 


\section{Persentase}

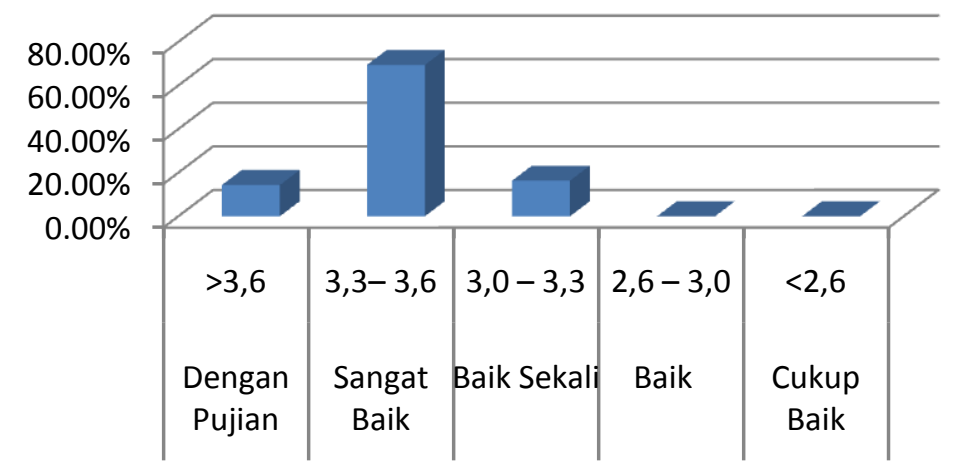

Gambar 9. Histogram Pengkategorian Hard SkillBerdasarkan IPK

\section{Pembahasan}

Berdasarkan hasil penelitian, maka dapat dibuat pembahasan tentang profilsoft skill danhard skill mahasiswadalammemasukiduniakerjatersebut.

\section{a. ProfilSoft Skill MahasiswadalamMemasukiDuniaKerja}

Berdasarkan hasil penelitian, maka dapat dikatakan bahwa secara keseluruhan profilsoft skillmahasiswadalammemasukiduniakerjadari 49 orang respondenberadadalamkategoritinggi dengan tingkat capaian 65\%yang terdiri dari: pada indikator etikakerja berada pada kategori tinggi yaitu dengan tingkat capaian 63\%, pada indikator kerjasama berada pada kategori tinggi yaitu dengan tingkat capaian 69,4\%, pada indikatorkecakapanberbahasaberada pada kategori sedangyaitu dengan tingkat capaian 44,9\%, pada indikatorpenyesuaianterhadapnorma-norma berada pada kategori tinggi yaitu dengan tingkat capaian 59\%, pada indikatordisiplin berada pada kategori tinggi yaitu dengan tingkat capaian $53,1 \%$, pada indikator percayadiriberada pada kategori sedangyaitu dengan tingkat capaian 69,39\%, dan pada indikator sopansantunberada pada kategori tinggi yaitu dengan tingkat capaian $61 \%$.

Berdasarkan data di atas dapat dilihat bahwa profil soft skill yang dimiliki mahasiswa Program Studi Pendidikan Kesejahteraan Keluarga dalam memasuki dunia kerja untuk indikator etika kerja, kerjasama, penyesuaian terhadap norma- norma, disiplin, dan sopan santun berada pada kategori tinggi. Untuk indikator kecakapan dalam berbahasa dan percaya diri berada pada kategori sedang. Sedangkan prioritas soft skill yang dibutuhkan di dunia kerja adalah kemampuan komunikasi, integritas, disiplin dan kerjasama. Berbeda dengan soft skill yang diprioritaskan oleh guru adalah etikaa dan moral serta komitmen dan disiplin (Didik Suryanto, 2013: 117).

Jadi, dari hasil penelitian tersebut dapat dilihat bahwa secara keseluruhan mahasiswa Program Studi Pendidikan Kesejahteraan Keluarga 
Jurusan Ilmu Kesejahteraan Keluarga Konsentrasi Tata Boga memiliki kemampuan dalam berhubungan dengan orang lain dan kemampuan mengatur dirinya sendiri serta mampu mengembangkan hasil kerjanya secara maksimal. Soft skill merupakan keterampilan seseorang dalam berhubungan dengan orang lain (termasuk dengan dirinya) semua profesi memerlukan soft skill (Zahraini, 2014: 357).

\section{b. Profil Hard Skill MahasiswadalamMemasukiDuniaKerja}

Berdasarkan hasil penelitian, maka dapat dikatakan bahwa secara keseluruhan profil hard skill mahasiswa dalam memasuki dunia kerja yang dilihat dari nilai IPK. Dilihat dari analisis data 49 orang responden tentang hard skill yang termasuk dalam kategori dengan pujian sebanyak 7 orang $(14,3 \%)$ kategori sangat baik sebanyak 34 orang $(69,4 \%)$, kategori baik sekali sebanyak 8 orang $(16,3 \%)$, kategori baik sebanyak 0 orang $(0 \%)$, dan kategori cukup baik sebanyak 0 orang (0\%). Dengan demikian berarti hard skill yang dimiliki mahasiswa S1 Tata Boga 2015 termasuk kategori sangat baik yaitu sebanyak 34 orang $(69,4 \%)$. Sehingga dapat diambil kesimpulan bahwa dari 49 responden mahasiswa Program Studi Pendidikan Kesejahteraan Keluarga mempunyai hard skill yang berkategori sangat baik.

Profil hard skill merupakan hal yang sangat penting dimiliki oleh mahasiswa dalam memasuki dunia kerja.Hard skill adalah pengetahuan dan kemampuan teknis yang dimiliki seseorang yang berhubungan dengan bidang ilmunya. Pengetahuan teknis yang dibutuhkan untuk profesi tertentu dan mengembangkannya sesuai dengan teknologi, mampu mengatasi masalah yang terjadi serta menganalisis (Alam, 2012: 14). Sedangkan Fitra Delita (2016:16) menyatakan bahwa, "Hard skill merupakan keterampilan yang dapat langsung dilihat hasilnya dalam proses pembelajaran, segera setelah proses pembelajaran tersebut selesai. Kemampuan tersebut biasanya diperoleh dari perkuliahan formal atau dari buku". Hasil penelitian ini mengungkapkan bahwa mahasiswa Program Studi Pendidikan Kesejahteraan Keluarga Jurusan Ilmu Kesejahteraan Keluarga Kontentrasi Tata Boga memiliki kemampuan hard skill yang sangat baik dengan persentase secara keseluruhan sebesar $69,4 \%$.

\section{KESIMPULAN}

Berdasarkan hasil penelitian mengenai profilsoft skilldanhard skillmahasiswadalammemasukiduniakerja dapat diambil kesimpulan sebagai berikut:

1. Profilsoft skillmahasiswadalammemasukiduniakerjadari 49 orang respondenmemilikisoft skill yang tidaksamatingginya. Dilihat dari indikator 
etika kerja, kerjasama, penyesuaian terhadap norma-norma, disiplin, sopan santun, kecakapan dalam berbahasa dan percaya diri. Berdasarkandariketujuhindikatortesebutterdapatduaindikator yang mendapatkankategorisedangyaitupadaindikatorkecakapandalamberbahasada npercayadiri. Hal ini sangat bertolak belakang dengan prioritas soft skill yang dibutuhkan oleh dunia kerja karena kemampuan dalam berkomunikasi dan percaya diri sangat diutamakan.

2. Profilhard skillyangdimilikimahasiswadilihatdariperolehan IPK termasuk kategori sangatbaik. Jadi, bisa disimpulkan bahwa mahasiswa memiliki hard skill yang dibutuhkan di dunia kerja.

\section{SARAN}

Berdasarkan kesimpulan yang telah dikemukakan, maka ada beberapa saran yang dapat dipertimbangkan adalah sebagai berikut:

1. Untuk mahasiswaagar sebaiknya lebih meningkatkan soft skillterutama pada kecakapan berbahasa dan percaya diri serta meningkatkanhard skill yang dimilikinya sehinggamemudahkanmahasiswa untuk memasukiduniakerja

2. Untuk peneliti lain agarsebaiknya melakukan penelitian lanjutan tentang profilsoft skilldanhard skillmahasiswadalammemasukiduniakerja dan mengetahui bagaimana profilsoft skilldanhard skillmahasiswadalammemasukiduniakerja.

\section{DAFTAR PUSTAKA}

Alam. 2012. "Analisa Pengaruh Hard Skill, Soft Skill dan Motivasi Terhadap Kinerja Tenaga Penjualan (Studi Pada Tenaga Kerja Penjualan PT.BUMIPUTERA Wilayah Semarang". Skripsi: Fakultas Ekonomik dan Bisnis Universitas Diponegoro.

Badan Pusat Statistik. 2019. “Tingkat Pengangguran Terbuka”. Diakses dari Diakses 01Oktober 2019.

Buku Pedoman Akademik Universitas Negeri Padang. 2011. Padang:Universitas Negeri Padang.

Cici Yoma Riza. 2013."Profil Lulusan Prodi Pendidikan Kesejahteraan Keluarga Fakultas Teknik Universitas Negeri Padang". Skripsi tidak diterbitkan. UNP.

Didik Suryanto, 2013. "Relevansi soft skill yang dibutuhkan dunia usaha/industri dengan yang dibelajarkan di sekolah menengah kejuruan". Jurnal Teknologi dan Kejuruan, Vol. 36, No. 2 , diakses 03 Oktober 2019.

Fitra Delita. 2016. "Peningkatan Soft Skills Dan Hard Skills Mahasiswa Melalui Project-Based Learning Pada Mata Kulah Perencanaan Pembelajaran Geografi". Jurnal Pendidikan Geografi, Universitas Negeri Medan Vol.8 No.2, 2016. 
Nissa Rizky. 2012. “Strategi Integrasi Soft SkillsDalam Pembelajaran Kompetensi Keahlian Administrasi Perkantoran DiSMK Negeri 1 Yogyakarta". Skripsi. Yogyakarta: Fakultas EkonomiUniversitas Negeri Yogyakarta.

Nurhasanah, N., Yulastri, A., \& Fridayati, L. (2016). Potensi Berwirausaha Mahasiswa Pendidikan Tata Boga Jurusan Ilmu Kesejahteraan Keluarga Universitas Negeri Padang. E-Journal Home Economic and Tourism, 13(3).

Tika Rusmiati. 2016. “Hubungan Pengalaman Lapangan Industri Dan Motivasi Kerja dengan Kesiapan Kerja Lulusan Program Studi Pendidikan Kesejahteraan Keluarga".Skripsi tidak diterbitkan. UNP.

Zahraini .2014. "Kinerja Dosen Dalam Meningkatkan Kemampuanakademik (Hard Skil) Dan Soft Skill) Pada Mahasiswa PKK FKIP UNSYIAH".Jurnal Ilmiah DIDAKDITA., (Online), Vol. XIV, No.2,(https://jurnal.ar-rainy.ac.id, diakses 20 Oktober 2019). 